\title{
New Insights into the Pathogenesis of Pancreatitis
}

\author{
Raghuwansh P. Sah, Rajinder K. Dawra, and Ashok K. Saluja \\ Department of Surgery, University of Minnesota, Minneapolis, MN 55455, USA
}

\begin{abstract}
Purpose of review-In this article, we review important advances in our understanding of the mechanisms of pancreatitis.

Recent Findings-The relative contribution of intra-pancreatic trypsinogen activation and NFKB activation, the two major early independent cellular events in the etiology of pancreatitis, have been investigated using novel genetic models. Trypsinogen activation has traditionally held the spotlight for many decades as it is believed to be the central pathogenic event of pancreatitis However, recent experimental evidence points to the role of trypsin activation in early acinar cell damage but not in the inflammatory response of acute pancreatitis through NFkB activation. Further, chronic pancreatitis in the caerulein model develops independently of typsinogen activation. Sustained activation of the NFKB pathway, but not persistent intra-acinar expression of active trypsin, was shown to result in chronic pancreatitis. Calcineurin-NFAT signaling was shown to mediate downstream effects of pathologic rise in intracellular calcium. IL-6 was identified as a key cytokine mediating pancreatitis-associated lung injury.

Summary—Recent advances challenge the long-believed trypsin-centered understanding of pancreatitis. It is becoming increasingly clear that activation of intense inflammatory signaling mechanisms in acinar cells is crucial to the pathogenesis of pancreatitis, which may explain the strong systemic inflammatory response in pancreatitis.
\end{abstract}

\section{Keywords}

Trypsin; NFkB; acute pancreatitis; chronic pancreatitis

\section{Introduction}

Pancreatitis, whether acute or chronic, is a cause of significant morbidity and mortality(1). There is at this time no targeted treatment for pancreatitis owing to the lack of understanding of its pathogenesis. The notion of pathologic autodigestion by the digestive enzymes synthesized and secreted by the pancreas as a result of premature intra-pancreatic activation, seems a natural possibility and forms the basis of the century-old autodigestion-centered theory of pancreatitis $(2,3)$ (Figure 1). Concerted research efforts in the 1980s and 1990s focused upon the mechanisms of premature digestive enzyme activation, and these led to significant advances in our knowledge of intracellular events in the initiation and progression of pancreatitis (4-7). Pathologic calcium signaling, subcellular redistribution leading to colocalization of lysosomal and zymogen components, early activation of NFkB pathway, identification of the processes of ER stress and autophagy in acinar cells, effects of redox signaling and oxidative stress, pathologic role of cellular and extracellular $\mathrm{pH}$ changes and the role of bile duct epithelial cells during pancreatitis have all been reviewed in our

Corresponding author: Ashok K. Saluja, 420 Delaware Street SE, Mayo Mail Code 195, Minneapolis, MN 55455, asaluja@umn.edu, Telephone: 612-624-8108 (O), Fax: 612-624-8909.

Conflict of interest: None to disclose 
previous articles $(2,3)$. In this article, we review important recent advances in the field since the last review period. These articles are intended to collectively present a comprehensive discussion of the pathogenesis of pancreatitis.

We present first the developments relating to the existing trypsin-centered theory of pancreatitis and examine them in detail with a focus on their implications and then discuss alternative hypotheses.

Following this, we discuss growing evidence supporting a novel paradigm of pancreatitis in which inflammatory signals from acinar cells trigger intense local and systemic inflammatory responses.

\section{The trypsin-centered theory}

Activation of trypsinogen to trypsin, the first step in the physiologic digestive enzyme cascade activation that occurs in the duodenum, has been confirmed to occur pathologically within the pancreas in most experimental models of pancreatitis (6-10). A plausible scenario, which is implicitly assumed by the trypsin-centered theory of pancreatitis (Figure $1)$, is that premature trypsinogen activation is directly pathogenic in pancreatitis $(2,8)$. However, several other possibilities exist (8): the detectable premature trypsinogen activation -1) may not be pathologically significant quantitatively, or 2) may be adequately cleared by protective responses within the acinar cell, or 3) may trigger pathologic acinar cell inflammatory signaling without direct cell damage, or 4) may cause some direct cell damage, trigger protective and pathologic cellular pathways such as autophagy and ER stress, and activate pathologic inflammatory signaling, or as a few experts have suggested $(5,11)$ may even be a protective response. Alternatively, other potential important trypsinindependent pathologic events may be present in sufficient degree to cause pancreatitis independently or in conjunction of trypsin-related injury (12). Thus, the causality of premature trypsinogen activation and pancreatitis cannot be an obvious assumption without rigorous proof. Experiments using protease inhibitors, with their questionable target specificity in suppressing trypsin activity, failed to provide any resolution $(13,14)$. Fortunately, genetic models specifically lacking pathologic trypsinogen activation (such as mice lacking trypsinogen-7 (T-/-) (12) or cathepsin B (CB-/-) (15) have now emerged, permitting the design of exciting experiments that permit unambiguous reexamination of the trypsin-centered theory of pancreatitis.

\section{Premature trypsinogen activation and early acinar injury in acute pancreatitis}

The extent of acinar necrosis was reduced by half in T-/- mice during caerulein-induced acute pancreatitis (12). Similar results had previously been seen in CB-/- mice (15). However, local and systemic inflammation comparable to that seen in wild type mice (who do have pathologic trypsinogen activation $(12,15)$ ) developed in the absence of significant pathologic trypsinogen activation in both $\mathrm{T}-/-$ and $\mathrm{CB}-/-$ mice. Thus, premature trypsinogen activation seems to contribute to a component of local injury but inflammation, both local and systemic, which is the hallmark of acute pancreatitis responsible for high morbidity and mortality, progresses independently of trypsinogen activation during acute pancreatitis $(3,12)$.

In vitro studies using $\mathrm{T}-/-$ acini showed no induction of cell death with supramaximal caerulein stimulation, which induces necrosis in acini from wild type mice (12). However, apoptosis occurred with transfection-mediated intra-acinar expression of active trypsin (in mouse acini) (16) or of mutated trypsinogens (in rat AR42J cells) (17). Thus both necrosis and apoptosis are induced by active trypsin, but the mechanism is not known although involvement of lysosomal membrane permeability has been postulated (Saluja A, 
unpublished observations). Both caspase-dependent and -independent mechanisms have been demonstrated (16).

However, trypsin-induced acinar cell death in experimental conditions does not by itself validate the belief that premature trypsinogen activation is sufficient to induce the systemic complications of acute pancreatitis. In an interesting mouse study using inducible expression of active trypsin specific to pancreatic acini, only rapid inductions with maximal expression (in homozygotes) resulted in acute pancreatitis, while gradual repetitive inductions or milder expression (in heterogyzotes) were not sufficient (18). Thus, it is apparent that not all detectable trypsin activity necessarily implies pathogenicity. However, most experimental pancreatitis studies continue to mechanistically link the pathologic events being investigated to detectable trypsinogen activation (19-21).

The response of pancreatic acini to trypsinogen activation seems to be rapid induction of cell death, and this may be a primarily protective response (18). Nonetheless, when overwhelming, as in caerulein-induced pancreatitis, cell death resulting from premature trypsinogen activation accounts for the early pancreatic injury during acute pancreatitis that is notably lacking in T-/- and CB-/- mice $(12,15)$ (Figure 2).

\section{Trypsin and pancreatitis susceptibility genes}

The biggest support for the trypsin-centered theory comes from identification of mutations in the cationic trypsinogen gene PRSS1 found in hereditary pancreatitis (22), an uncommon form of pancreatitis with autosomal dominant inheritance. Over the last decade, several additional mutations have been associated with familial as well as alcoholic and non-familial forms of chronic pancreatitis (23-26). Five pancreatitis susceptibility genes have now been well established: 1) cationic trypsinogen (PRSS1), 2) cystic fibrosis transmembrane conductance regulator $(C F T R), 3)$ pancreatic secretory trypsin inhibitor or serine protease inhibitor kazal type $1(S P I N K 1), 4)$ chymotrypsinogen $\mathrm{C}(C T R C)$, and 5) calcium-sensing receptor $(C A S R)(23,26)$.

Increased trypsinogen activation resulting from the recognized mutations in these susceptibility genes has been postulated to be the mechanism of pancreatic injury (23-26). This hypothesis is the most plausible mechanistic explanation, but it lacks any direct evidence, as is well illustrated by investigations on PRSS, the best-studied among these genes. Increased trypsinogen activation has been demonstrated in the test tube for only a few of the PRSS1 mutations $(27,28)$, but their expression in human embryonic kidney (HEK) cell lines suggests that intracellular trypsinogen activation may not occur (29). No evidence of increased trypsinogen activation was found in mice expressing the most common p.R122H PRSS1 mutant (30). It has also been recognized that, in a few cases, these mutations may be incidental $(31,32)$. Further the trypsinogen activation hypothesis of hereditary pancreatitis does not explain incomplete penetrance, intermittent nature of the disease, and lack of progression to CP in some individuals despite recurrent episodes (3335). However, emerging epidemiologic and genetic data continue to be linked to trypsinogen activation $(23,25,36-39)$. On the contrary, it is becoming increasingly clear that with the exception of hereditary pancreatitis and cystic fibrosis, a direct simplistic genetic mechanism may not exist but that instead, a complex interplay between genetic, environmental and developmental factors governs the susceptibility, progression and severity of pancreatitis $(23,40)$.

\section{Premature trypsinogen activation and chronic pancreatitis}

Traditionally, the pathogenesis of chronic pancreatitis has been mostly deduced as a natural extension of acute pancreatitis. Despite the tendency to clump these entities together, 
assumptions from acute pancreatitis are speculative at best, since the relationship between acute and chronic pancreatitis is not clear $(33,41-44)$. Nevertheless, as for acute pancreatitis, the popular belief persists that intra-pancreatic trypsinogen activation is responsible for the pathogenesis of chronic pancreatitis. This theory is primarily supported by the observation that PRSS1 mutations of hereditary pancreatitis, and as described earlier, bear a complementary relationship with the proposed trypsinogen activation theory of other pancreatitis susceptibility genes $(24,26,45)$.

Interestingly, prolonged expression of active trypsin in mouse pancreatic acinar cells in an in vivo genetic model resulted in acinar cell loss but was not sufficient to cause chronic pancreatitis (18). Conversely, T-/- and CB-/- mice lacking pathologic intra-acinar trypsinogen activation developed chronic pancreatitis indistinguishable from that in wild type mice, suggesting that the pathogenesis of chronic pancreatitis is independent of trypsinogen activation (46). These data, although limited by lack of validation in multiple experimental models, challenge the existing trypsin-centered theory of chronic pancreatitis. Further confirmation of the results just described awaits the development of alternative experimental mouse models of chronic pancreatitis where existing genetic manipulations such as knockout of trypsinogen-7 can be applied.

\section{Inflammatory signaling in acinar cells}

Pancreatic acinar cells are unique in the human body- they have the highest rate of protein synthesis and produce large quantities of digestive enzymes (47). Conceivably, these cells have unique properties to maintain their functionality, stability and self-protection. One of these seems to be their inflammatory properties (3). Emerging evidence from acinar cells points to early and sustained activation of inflammatory signaling that is responsible for the intense local and systemic inflammatory response seen in acute pancreatitis (Figure 2) and the development of the chronic inflammation and fibrosis of chronic pancreatitis (Figure 3). The NFkB pathway is the best described inflammatory signaling pathway in the pancreatic acinar cell (48).

\section{Activation of NFkB in acinar cells}

Though the activation of $\mathrm{NF \kappa B}$ within the acinar cell during pancreatitis had been previously recognized (49-51), it is only recently that its significance is becoming apparent. The matter has been debated as a potential consequence of premature trypsinogen activation for over a decade $(2,52)$, but recent data from $\mathrm{T}-/-$ and $\mathrm{CB}-/-$ mice (12) and in vitro expression of active trypsin within acini using transfection (16) confirm that intra-acinar $\mathrm{NF \kappa B}$ activation occurs very early in pancreatitis independent of trypsinogen activation. Further, activation of $\mathrm{NFkB}$ in acinar cells has been shown to result in severe acute pancreatitis with local injury and systemic inflammatory response in several genetic models including adenovirus-mediated transfection of activated NFKB in the acinar cells by intraductal injection (53) and in two separate models of inducible expression of active IKK2 targeted to pancreatic acinar cells $(54,55)$. In addition, inhibition of $\mathrm{NF} \kappa \mathrm{B}$ in genetic models, e.g. mice with constitutional and global deletion of $\mathrm{NF \kappa B}$ p50 subunit (56) and pancreas-specific expression of inducible inactive IKK2 (54), as well as pharmacologic studies $(48,57,58)$, have been shown to result in attenuated pancreatitis response with severity inversely proportional to the degree of $\mathrm{NF} \kappa \mathrm{B}$ inhibition. In another recent genetic model, pancreas-specific inducible expression of NFKB p65/RelA subunit led to compensatory expression of IkBa leading to unclear phenotype at baseline but increased severity of acute pancreatitis with even mild caerulein stimulation (55). When this model was combined with inducible pancreas-specific expression of active IKK2 that resulted in inducible p65 and active IKK2 co-expression in the pancreas (55), spontaneous severe acute 
pancreatitis was the result. This highlights the role of induction of the NFkB pathway in causing acute pancreatitis.

\section{Sustained intra-acinar NFKB activation in chronic pancreatitis}

Sustained activation of NFkB in the acinar cells was seen in the caerulein model of chronic pancreatitis in WT as well as T-/- and CB-/- mice lacking significant intra-acinar trypsinogen activation (46). Chronic intra-acinar $\mathrm{NF \kappa B}$ activation was further confirmed in human chronic pancreatitis (46). Based on these data, it was suggested that sustained activation of inflammatory pathways in pancreatic acinar cells results in chronic pancreatitis (46) (Figure 3).

Recent experimental data support this theory of sustained intra-acinar NFkB activation. Inducible expression of NFkB p65/RelA in pancreatic acini led to induction of severe chronic pancreatitis within 6 weeks of weekly episodes of caerulein-induced mild acute pancreatitis (55). These repeated episodes of mild acute pancreatitis failed to result in chronic pancreatitis in the wild type mice (55). Further, the prolonged expression of inducible active IKK2 in pancreatic acini resulted in spontaneous severe chronic pancreatitis (55).

Persistence of the stimulus, which may be any of the recognized etiologies (such as alcohol, bile exposure, increased ductal pressure, intracellular accumulation of mutated proteins, autoimmune sensitization, etc), may drive the sustained intra-acinar activation of the inflammatory pathways in chronic pancreatitis (46). In line with this theory, it has been demonstrated in alcohol-related pancreatic injury that withdrawal of the stimulus may lead to disease reversal at least in the early stages (59). A complex interplay of genetics, environmental and structural factors may influence the effects of the pathogenic stimuli (46). This novel paradigm of chronic pancreatitis, contrary to the prior theories, does not require trypsinogen activation, necrosis-fibrosis sequence, acute-to-chronic pancreatitis progression or a sentinel episode of acute pancreatitis $(33,41,42,45)$.

\section{Constitutive vs inducible NFKB model paradox}

In contrast to observations in the inducible models of $\mathrm{NF \kappa B}$ described above (with the exception of one constitutive mouse model with global deletion of p50), Algul et al (21, 60, 61) report paradoxical results in models with constitutive NFkB genetic modifications.

Pancreas-specific truncation of p65/RelA led to increased severity of acute pancreatitis (60) as well as chronic pancreatitis (61) induced with caerulein. Mice with deletion of IkBa in the pancreas demonstrated constitutive $\mathrm{NF \kappa B}$ activation, which attenuated the pancreatitis response, and this effect could be reversed by combined deletion of p65/RelA and IkBa (21). This group has proposed a protective role for $\mathrm{NFKB}$ activation in the acinar cell due to induction of pancreatitis associated protein (PAP) and serine protease inhibitor $2 \mathrm{~A}$ (spi2A, which has been linked to diminished trypsinogen activation) $(21,60)$.

The authors argue that NFKB activation in the myeloid cells of the inflammatory infiltrate is responsible for inflammation in acute pancreatitis $(21,60)$ and in fibrosis and stellate cell activation in chronic pancreatitis (61). Interestingly, deletion of p65/RelA in the myeloid cells alone did not lead to any difference in pancreatitis response compared with that in wild type mice (61). While the paradox remains to be definitively resolved, one possible explanation may be disruption of the broad spectrum of NFkB -dependent processes $(62,63)$ in the pancreas in the constitutive models, which probably remain unaffected or minimally affected in the inducible/conditional models. Such an example was recently demonstrated in pancreatic acinar cells in a constitutive model of IKK1 deletion, which led to reduced autophagic degradation independently of $\mathrm{NF \kappa B}$ activity and increased spontaneous 
pancreatitis by induction of ER stress and oxidative stress (64). Undoubtedly, the diversity of $\mathrm{NF \kappa B}$-regulated processes and lack of a clear understanding of the fine tuning between physiological and pathological responses (63) lend great complexity to these experimental models.

\section{Cytokines}

Zhang et al (65) produced a model of severe acute pancreatitis with lung injury by using IL6-deficient mice and a modified protocol of caerulein pancreatitis where mild acute pancreatitis was repeated consecutively for five days. They showed here that IL6 mediates pancreatitis-induced lung injury through complexation with its soluble receptor (sIL6R), a process known as trans-signaling (65). The IL6-sIL6R complex led to STAT3 activation in the pancreatic acini while myeloid NFKB activation induced IL6 production (65). IL22 was found to be protective in acute pancreatitis and identified as a potential therapeutic option (66). Aryl hydrocarbon receptors (AhR) on CD4 cells were required for IL22 production and AhR-deficient mice developed severe pancreatitis which could be rescued by exogenous administration of IL22 (66). Overexpression of IL22 receptors on acinar cells occurred in acute pancreatitis (66).

\section{Other pathologic mechanisms}

Pathologic calcium signal is generated in pancreatic acinar cells as an immediate response to pathologic stimuli (discussed in detail in our previous reviews $(2,3)$ ). This signal has been shown to be transmitted through calcineurin activation (20). When inhibited pharmacologically and via genetic deletion, calcineurin was shown to reduce bile-induced pancreatitis in mice (20). Further downstream target of calcineurin activation was identified as the family of 4 transcription factors: nuclear factor of activated T-cells (NFAT c1-4). Inhibition of NFATc3 was shown to attenuate pancreatitis (19).

ER stress and activation of unfolded protein response, recently recognized in acute pancreatitis $(2,3,67)$, were shown to be sustained in chronic pancreatitis (unpublished observations, Sah and Saluja). Pancreatic acinar cells, owing to their dependence on high ER volume and functionality, are especially susceptible to perturbations in ER homeostasis.

Autophagy and lysosomal dysfunction are being investigated intensively as crucial cellular events in pancreatitis (68). SPINK3/PSTI (mouse correlate of SPINK1 in humans) has been shown to affect autophagy as well as several other processes including inflammation and proliferation $(38,39,69)$, which may explain the attenuated pancreatitis observed in mice overexpressing SPINK3/PSTI $(70,71)$. Retarded progression of autophagy has been linked to pathogenesis of pancreatitis $(68,72)$, an effect demonstrated recently in numerous models such as pancreas-specific IKK1-deleted mice (64), interferon regulatory factor 2 (IRF 2)deleted mice (73) and mice overexpressing IL22 (74).

The multiple pathologic cellular events identified in acute pancreatitis, i.e. autophagy, ER stress, oxidative stress, lysosomal and mitochondrial dysfunction may be interdependent and may eventually contribute to sustained acinar cell inflammatory signaling that leads to acute pancreatitis, as described in our prior article (Figure 4 in ref. (3)) (Figure 2).

Pancreatic acinar cells, consequent to the activation of inflammatory signaling, lead to generation of NGF, $\mathrm{H}^{+}$and other neurotrophic factors that activate receptors in the pancreatic afferents such as TRPV1, TRPA1 and PAR2, and this leads to generation of neurokines and bradykinins, which induce neuro-inflammation (75). The role of neuroinflammation in pancreatitis is not fully characterized apart from generation of pain, although it may lead to augmentation of the pancreatic inflammatory response. Recently, 
TRPV1 and TRPA1 channels have been shown to be important in chronic inflammation (76).

\section{Conclusion}

Genetic models of trypsin expression and models lacking trypsinogen activation have led to exciting results that challenge the century-old trypsin-centered theory of pancreatitis. It is becoming increasingly clear that activation of intense inflammatory signaling mechanisms in acinar cells is crucial to the pathogenesis of pancreatitis, which may explain the strong systemic inflammatory response in pancreatitis.

\section{Acknowledgments}

Grant support:

- $\quad$ NIH R01 DK093047

- $\quad$ NIH R01 DK092145

- $\quad$ NIH R01 DK058694

\section{References}

1. Yadav D, Lowenfels AB. The epidemiology of pancreatitis and pancreatic cancer. Gastroenterology. 2013; 144(6):1252-61.

2. Sah RP, Saluja A. Molecular mechanisms of pancreatic injury. Curr Opin Gastroenterol. 2011; 27(5):444-51.

3. Sah RP, Garg P, Saluja AK. Pathogenic mechanisms of acute pancreatitis. Current Opin in Gastroenterol. 2012; 28(5):507-15.

4. Saluja A, Hashimoto S, Saluja M, et al. Subcellular redistribution of lysosomal enzymes during caerulein-induced pancreatitis. Am J Physiol. 1987; 253(4 Pt 1):G508-16.

5. Lerch MM, Gorelick FS. Early trypsinogen activation in acute pancreatitis. Med Clin North Am. 2000; 84(3):549-63. viii.

6. Gorelick FS, Thrower E. The acinar cell and early pancreatitis responses. Clin Gastroenterol Hepatol. 2009; 7(11 Suppl):S10-4.

7. Saluja AK, Lerch MM, Phillips PA, et al. Why does pancreatic overstimulation cause pancreatitis? Annu Rev Physiol. 2007; 69:249-69.

8. Sah RP, Saluja AK. Trypsinogen activation in acute and chronic pancreatitis: is it a prerequisite? Gut. 2011; 60(10):1305-7.

9. Kloppel G, Dreyer T, Willemer S, et al. Human acute pancreatitis: its pathogenesis in the light of immunocytochemical and ultrastructural findings in acinar cells. Virchows Arch A Pathol Anat Histopathol. 1986; 409(6):791-803.

10. Hofbauer B, Saluja AK, Lerch MM, et al. Intra-acinar cell activation of trypsinogen during caerulein-induced pancreatitis in rats. Am J Physiol. 1998; 275(2 Pt 1):G352-62.

11. Halangk W, Kruger B, Ruthenburger M, et al. Trypsin activity is not involved in premature, intrapancreatic trypsinogen activation. Am J Physiol Gastrointest Liver Physiol. 2002; 282(2):G367-74.

12. Dawra R, Sah RP, Dudeja V, et al. Intra-acinar trypsinogen activation mediates early stages of pancreatic injury but not inflammation in mice with acute pancreatitis. Gastroenterology. 2011; 141(6):2210-7.

13. Singh VP, Chari ST. Protease inhibitors in acute pancreatitis: lessons from the bench and failed clinical trials. Gastroenterology. 2005; 128(7):2172-4.

14. Seta T, Noguchi Y, Shimada T, et al. Treatment of acute pancreatitis with protease inhibitors: a meta-analysis. Eur J Gastroenterol Hepatol. 2004; 16(12):1287-93.

15. Halangk W, Lerch MM, Brandt-Nedelev B, et al. Role of cathepsin B in intracellular trypsinogen activation and the onset of acute pancreatitis. J Clin Invest. 2000; 106(6):773-81. 
16. Ji B, Gaiser S, Chen X, et al. Intracellular trypsin induces pancreatic acinar cell death but not NFkappaB activation. J Biol Chem. 2009; 284(26):17488-98.

17. Kereszturi E, Sahin-Toth M. Intracellular autoactivation of human cationic trypsinogen mutants causes reduced trypsinogen secretion and acinar cell death. J Biol Chem. 2009; 284(48):33392-9.

18. Gaiser S, Daniluk J, Liu Y, et al. Intracellular activation of trypsinogen in transgenic mice induces acute but not chronic pancreatitis. Gut. 2011; 60:179-88.

19. Awla D, Zetterqvist AV, Abdulla A, et al. NFATc3 regulates trypsinogen activation, neutrophil recruitment, and tissue damage in acute pancreatitis in mice. Gastroenterology. 2012; 143(5): 1352-60.

20. Muili KA, Wang D, Orabi AI, et al. Bile acids induce pancreatic acinar cell injury and pancreatitis by activating calcineurin. J Biol Chem. 2013; 288(1):570-80. 10 1074/jbc M112 428896. [doi].

21. Neuhofer P, Liang S, Einwachter H, et al. Deletion of IkappaBalpha activates RelA to reduce acute pancreatitis in mice through up-regulation of Spi2A. Gastroenterology. 2013; 144(1):192-201.

22. Whitcomb DC, Gorry MC, Preston RA, et al. Hereditary pancreatitis is caused by a mutation in the cationic trypsinogen gene. Nat Genet. 1996; 14(2):141-5.

23. Whitcomb DC. Genetics of alcoholic and nonalcoholic pancreatitis. Curr Opin Gastroenterol. 2012; 28(5):501-6.

24. Whitcomb DC. Genetic aspects of pancreatitis. Annu Rev Med. 2010; 61:413-24. [PubMed: 20059346]

25. LaRusch J, Whitcomb DC. Genetics of pancreatitis. Curr Opin Gastroenterol. 2011; 27(5):467-74.

26. Chen JM, Ferec C. Chronic pancreatitis: genetics and pathogenesis. Annu Rev Genomics Hum Genet. 2009; 10:63-87.

27. Teich N, Rosendahl J, Toth M, et al. Mutations of human cationic trypsinogen (PRSS1) and chronic pancreatitis. Hum Mutat. 2006; 27(8):721-30.

28. Sahin-Toth M. Biochemical models of hereditary pancreatitis. Endocrinol Metab Clin North Am. 2006; 35(2):303-12. [PubMed: 16632094]

29. Kereszturi E, Szmola R, Kukor Z, et al. Hereditary pancreatitis caused by mutation-induced misfolding of human cationic trypsinogen: a novel disease mechanism. Hum Mutat. 2009; 30(4): 575-82. [PubMed: 19191323]

30. Archer H, Jura N, Keller J, et al. A mouse model of hereditary pancreatitis generated by transgenic expression of R122H trypsinogen. Gastroenterology. 2006; 131(6):1844-55. [PubMed: 17087933]

31. Szmola R, Sahin-Toth M. Uncertainties in the classification of human cationic trypsinogen (PRSS1) variants as hereditary pancreatitis-associated mutations. J Med Genet. 2010; 47(5):34850.

32. Rosendahl J, Teich N, Kovacs P, et al. Complete analysis of the human mesotrypsinogen gene (PRSS3) in patients with chronic pancreatitis. Pancreatology. 2010; 10(2-3):243-9. [PubMed: 20484962]

33. Whitcomb DC. Mechanisms of disease: Advances in understanding the mechanisms leading to chronic pancreatitis. Nat Clin Pract Gastroenterol Hepatol. 2004; 1(1):46-52.

34. Rebours V, Boutron-Ruault MC, Schnee M, et al. The natural history of hereditary pancreatitis: a national series. Gut. 2009; 58(1):97-103.

35. Howes N, Lerch MM, Greenhalf W, et al. Clinical and genetic characteristics of hereditary pancreatitis in Europe. Clin Gastroenterol Hepato. 2004; 2(3):252-61.

36. Mahurkar S, Idris MM, Reddy DN, et al. Association of cathepsin B gene polymorphisms with tropical calcific pancreatitis. Gut. 2006; 55(9):1270-5. [PubMed: 16492714]

37. Paliwal S, Bhaskar S, Mani KR, et al. Comprehensive screening of chymotrypsin C (CTRC) gene in tropical calcific pancreatitis identifies novel variants. Gut. 2012

38. Ohmuraya M, Sugano A, Hirota M, et al. Role of Intrapancreatic SPINK1/Spink3 expression in the development of pancreatitis. Front Physiol. 2012; 3:126.

39. Ohmuraya M, Yamamura K. Roles of serine protease inhibitor Kazal type 1 (SPINK1) in pancreatic diseases. Exp Anim. 2011; 60(5):433-44. 
40. Whitcomb DC, Larusch J, Krasinskas AM, et al. Common genetic variants in the CLDN2 and PRSS1-PRSS2 loci alter risk for alcohol-related and sporadic pancreatitis. Nat Genetics. 2012; 44(12):1349-54.

41. Witt H, Apte MV, Keim V, et al. Chronic pancreatitis: challenges and advances in pathogenesis, genetics, diagnosis, and therapy. Gastroenterology. 2007; 132(4):1557-73.

42. Apte MV, Pirola RC, Wilson JS. Mechanisms of alcoholic pancreatitis. J Gastroenterol Hepatol. 2010; 25(12):1816-26.

43. Yadav D, O’Connell M, Papachristou GI. Natural history following the first attack of acute pancreatitis. Am J Gastroenterol. 2012; 107(7):1096-103.

44. Guda NM, Romagnuolo J, Freeman ML. Recurrent and relapsing pancreatitis. Curr Gastroenterol Rep. 2011; 13(2):140-9.

45. Etemad B, Whitcomb DC. Chronic pancreatitis: diagnosis, classification, and new genetic developments. Gastroenterology. 2001; 120(3):682-707.

46. Sah RP, Dudeja V, Dawra RK, et al. Cerulein-induced chronic pancreatitis does not require intraacinar activation of trypsinogen in mice. Gastroenterology. 2013; 144(5):1076-85. e2.

47. Case RM. Synthesis, intracellular transport and discharge of exportable proteins in the pancreatic acinar cell and other cells. Biol Rev Camb Philos Soc. 1978; 53(2):211-354.

48. Rakonczay Z Jr, Hegyi P, Takacs T, et al. The role of NF-kappaB activation in the pathogenesis of acute pancreatitis. Gut. 2008; 57(2):259-67.

49. Han B, Ji B, Logsdon CD. CCK independently activates intracellular trypsinogen and NF-kappaB in rat pancreatic acinar cells. Am J Physiol Cell Physiol. 2001; 280(3):C465-72. [PubMed: 11171565]

50. Gukovsky I, Gukovskaya AS, Blinman TA, et al. Early NF-kappaB activation is associated with hormone-induced pancreatitis. Am J Physiol. 1998; 275(6 Pt 1):G1402-14. [PubMed: 9843778]

51. Hietaranta AJ, Saluja AK, Bhagat L, et al. Relationship between NF-kappaB and trypsinogen activation in rat pancreas after supramaximal caerulein stimulation. Biochem Biophys Res Commun. 2001; 280(1):388-95.

52. Tando Y, Algul H, Schneider G, et al. Induction of IkappaB-kinase by cholecystokinin is mediated by trypsinogen activation in rat pancreatic lobules. Digestion. 2002; 66(4):237-45.

53. Chen X, Ji B, Han B, et al. NF-kappaB activation in pancreas induces pancreatic and systemic inflammatory response. Gastroenterology. 2002; 122(2):448-57.

54. Baumann B, Wagner M, Aleksic T, et al. Constitutive IKK2 activation in acinar cells is sufficient to induce pancreatitis in vivo. J Clin Invest. 2007; 117(6):1502-13.

55. Huang H, Liu Y, Daniluk J, et al. Activation of nuclear factor-kappaB in acinar cells increases the severity of pancreatitis in mice. Gastroenterology. 2013; 144(1):202-10. [PubMed: 23041324]

56. Altavilla D, Famulari C, Passaniti M, et al. Attenuated cerulein-induced pancreatitis in nuclear factor-kappaB-deficient mice. Lab Invest. 2003; 83(12):1723-32.

57. Satoh A, Shimosegawa T, Fujita M, et al. Inhibition of nuclear factor-kappaB activation improves the survival of rats with taurocholate pancreatitis. Gut. 1999; 44(2):253-8.

58. Rakonczay Z Jr, Duda E, Kaszaki J, et al. The anti-inflammatory effect of methylprednisolone occurs down-stream of nuclear factor-kappaB DNA binding in acute pancreatitis. Eur J Pharmacol. 2003; 464(2-3):217-27.

59. Vonlaufen A, Phillips PA, Xu Z, et al. Withdrawal of alcohol promotes regression while continued alcohol intake promotes persistence of LPS-induced pancreatic injury in alcohol-fed rats. Gut. 2011; 60(2):238-46.

60. Algul H, Treiber M, Lesina M, et al. Pancreas-specific RelA/p65 truncation increases susceptibility of acini to inflammation-associated cell death following cerulein pancreatitis. J Clin Invest. 2007; 117(6):1490-501.

61. Treiber M, Neuhofer P, Anetsberger E, et al. Myeloid, but not pancreatic, RelA/p65 is required for fibrosis in a mouse model of chronic pancreatitis. Gastroenterology. 2011; 141(4):1473-85. 85 e17.

62. Shen HM, Tergaonkar V. NFkappaB signaling in carcinogenesis and as a potential molecular target for cancer therapy. Apoptosis. 2009; 14(4):348-63. 
63. Vallabhapurapu S, Karin M. Regulation and function of NF-kappaB transcription factors in the immune system. Annu Rev Immunol. 2009; 27:693-733.

64. Li N, Wu X, Holzer RG, et al. Loss of acinar cell IKKalpha triggers spontaneous pancreatitis in mice. J Clin Invest. 2013; 123(5):2231-43.

65. Zhang H, Neuhofer P, Song L, et al. IL-6 trans-signaling promotes pancreatitis-associated lung injury and lethality. J Clin Invest. 2013; 123(3):1019-31. [PubMed: 23426178]

66. Xue J, Nguyen DT, Habtezion A. Aryl hydrocarbon receptor regulates pancreatic IL-22 production and protects mice from acute pancreatitis. Gastroenterol. 2012; 143(6):1670-80.

67. Kubisch CH, Logsdon CD. Secretagogues differentially activate endoplasmic reticulum stress responses in pancreatic acinar cells. Am J Physiol Gastrointest Liver Physiol. 2007; 292(6):G1804-12.

68. Gukovskaya AS, Gukovsky I. Autophagy and pancreatitis. Am J Physiol Gastrointest Liver Physiol. 2012; 303(9):G993-G1003.

69. Ohmuraya M, Hirota M, Araki M, et al. Autophagic cell death of pancreatic acinar cells in serine protease inhibitor Kazal type 3-deficient mice. Gastroenterology. 2005; 129(2):696-705.

70. Nathan JD, Romac J, Peng RY, et al. Protection against chronic pancreatitis and pancreatic fibrosis in mice overexpressing pancreatic secretory trypsin inhibitor. Pancreas. 2010; 39(1):e24-30.

71. Nathan JD, Romac J, Peng RY, et al. Transgenic expression of pancreatic secretory trypsin inhibitor-I ameliorates secretagogue-induced pancreatitis in mice. Gastroenterology. 2005; 128(3): 717-27.

72. Mareninova OA, Hermann K, French SW, et al. Impaired autophagic flux mediates acinar cell vacuole formation and trypsinogen activation in rodent models of acute pancreatitis. J Clin Invest. 2009; 119(11):3340-55.

73. Mashima H, Sato T, Horie Y, et al. Interferon regulatory factor-2 regulates exocytosis mechanisms mediated by SNAREs in pancreatic acinar cells. Gastroenterology. 2011; 141(3):1102-13. e1-8.

74. Feng D, Park O, Radaeva S, et al. Interleukin-22 ameliorates cerulein-induced pancreatitis in mice by inhibiting the autophagic pathway. Int J Biol Sci. 2012; 8(2):249-57.

75. Schwartz ES, Christianson JA, Chen X, et al. Synergistic role of TRPV1 and TRPA1 in pancreatic pain and inflammation. Gastroenterology. 2011; 140(4):1283-91. e1-2.

76. Schwartz ES, La JH, Scheff NN, et al. TRPV1 and TRPA1 antagonists prevent the transition of acute to chronic inflammation and pain in chronic pancreatitis. J Neurosci. 2013; 33(13):5603-11. 


\section{Key points}

- Premature trypsinogen activation leads to acinar cell death, which, in turn, contributes to a component of acinar injury in acute pancreatitis.

- Pathogenesis of local and systemic inflammation occurs in acute pancreatitis independently of premature trypsinogen activation, challenging the century-old trypsin-centered theory of pancreatitis.

- Early, sustained intra-acinar NFkB activation is responsible for the intense inflammatory response of acute pancreatitis.

- Chronic pancreatitis in the caerulein model develops independently of intraacinar trypsinogen activation. Intra-acinar trypsin activation alone is not sufficient to result in chronic pancreatitis.

- Sustained activation of inflammatory pathways by persistent pathogenic stimuli such as $\mathrm{NF \kappa B}$ in the acinar cell is responsible for chronic pancreatitis. 


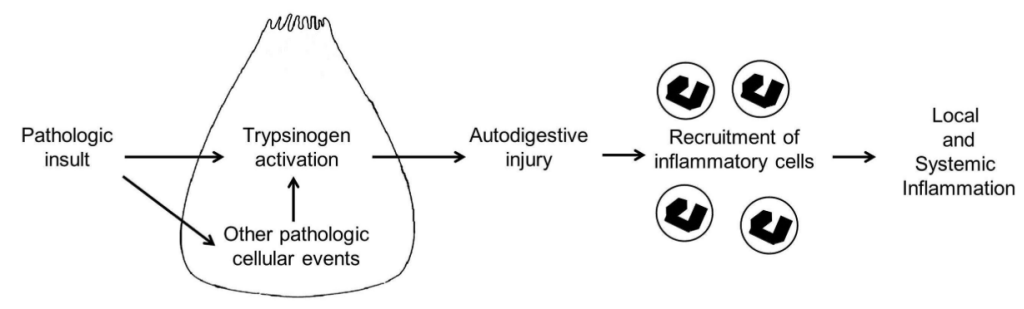

Figure 1. The trypsin-centered theory of pancreatitis

Intra-acinar trypsinogen activation is the central event in this theory and is responsible for local injury and systemic inflammation. Other pathologic events like ER stress, autophagy, lysosomal dysfunction, $\mathrm{pH}$ alterations, oxidative stress, bile duct dysfunction, etc (see text) are linked to the central event (trypsinogen activation) in this theory. 


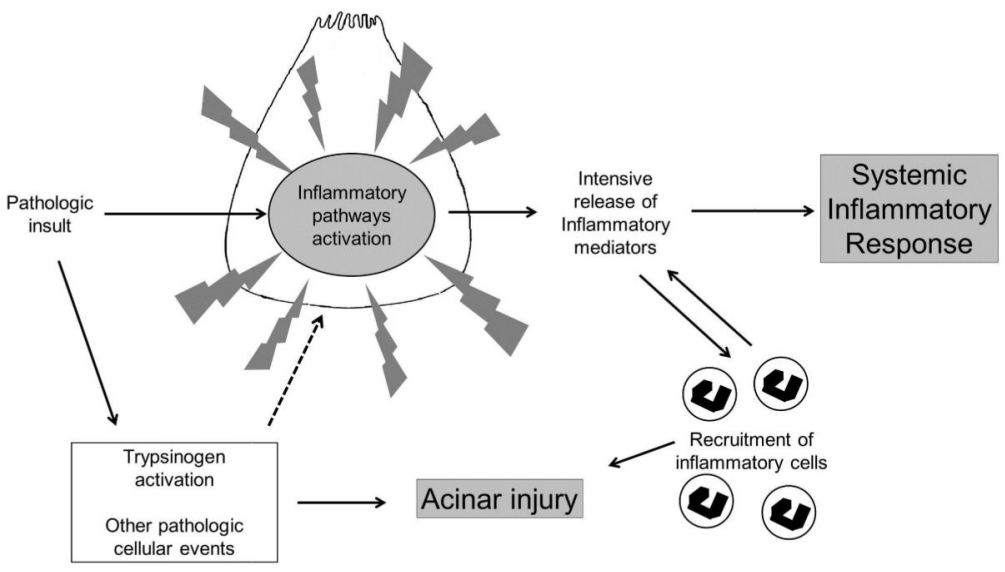

Figure 2. A schematic of the pathogenesis of acute pancreatitis

Activation of inflammatory pathways such as NFkB in the acinar cell leads to intense inflammatory reaction responsible for local injury and the systemic inflammatory response in acute pancreatitis. Trypsinogen activation seems to cause early acinar damage during acute pancreatitis. Other pathologic events like ER stress, autophagy, lysosomal dysfunction, $\mathrm{pH}$ alterations, oxidative stress, bile duct dysfunction, etc (see text) potentially augment and sustain the acinar cell inflammatory signalling leading to the intense inflammatory response. 


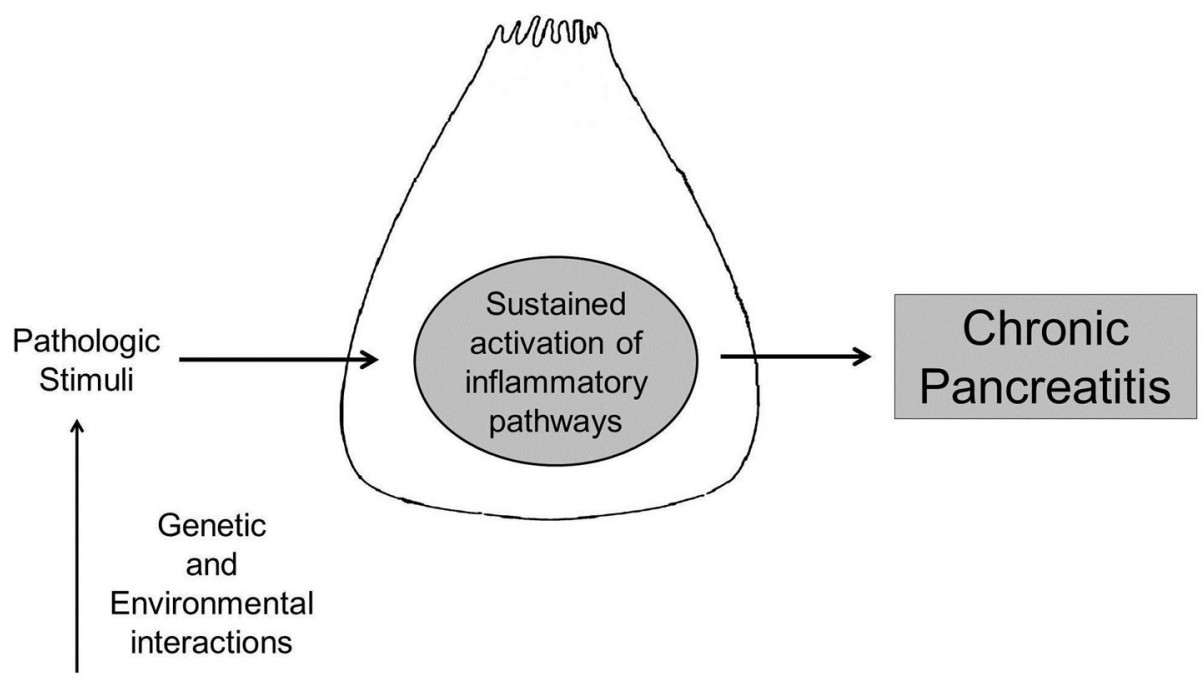

\section{- Alcohol \\ - Bile exposure \\ - Ductal obstruction \\ - Duct dysfunction \\ - Toxins (drugs, smoking) \\ - Hereditary mutations \\ - Autoimmune sensitization \\ - Viral infections}

Figure 3. Pathogenesis of chronic pancreatitis

Sustained activation of inflammatory pathways such as NFkB leads to the development of chronic pancreatitis. The recognized etiological associations of chronic pancreatitis are shown in the box, which may be the pathologic stimulus for sustained activation of acinar cell inflammatory pathways. The effect of these etiological associations seems to be modulated by genetic and environmental factors. See text for details. 